Original Article

\title{
ANTIOXIDANT ACTIVITY, PHYTOCHEMICAL ANALYSIS AND TOTAL POLYPHENOLICS CONTENT OF ESSENTIAL OIL, METHANOL EXTRACT AND METHANOL FRACTIONS FROM COMMELINA NUDIFLORA
}

\author{
MUHAMMAD DAWOOD SHAH, MOHAMMAD IQBAL \\ Biotechnology Research Institute, Universiti Malaysia Sabah, Jalan UMS, 88400 Kota Kinabalu, Sabah, Malaysia \\ Email: driqbalmohammad@gmail.com
}

Received: 14 Mar 2018 Revised and Accepted: 27 Jun 2018

\begin{abstract}
Objective: In the present study, the essential oil, methanol extract, and methanol fractions (n-hexane, chloroform, ethyl acetate, and n-butanol) obtained from Commelina nudiflora were investigated for the free radical scavenging effects and phytochemical analysis.

Methods: The antioxidative effect of the essential oil, methanol extracts and methanol fractions were evaluated using 2, 2 diphenyl-1-picrylhydrazyl (DPPH) radical scavenging assay. Total phenolic and flavonoid contents were determined using Folin-Ciocalteau and aluminium chloride reagents respectively. The phytochemical analyses of the essential oil, methanol extracts and methanol fractions were performed by gas chromatography and mass spectrometry (GCMS).

Results: The antioxidant, total phenolic and total flavonoid contents of butanol, ethyl acetate and chloroform fractions were higher followed by methanol extract, hexane fraction and essential oil. Phytochemical analysis indicated the presence of alkaloid, saponin, steroid, phytosterols, triterpenoids and tannins etc. The identified bioactive constituents of essential oil, methanol extract and methanol fractions of $C$. nudiflora were indole, 2-methoxy-4-vinylphenol, 2-pentadecanone, 6,10,14-trimethyl, phenol, benzyl alcohol, eugenol, phenol, 2, 4-bis (1,1dimethylethyl), hexadecanoic acid, ethyl ester (palmitic acid ester), n-hexadecanoic acid (palmitic acid), 9, 12-octadecadienoic acid, (linoleic acid) and phytol. All identified bioactive compounds and their derivatives were generally reported with antimicrobial, antioxidant, anti-
\end{abstract} inflammatory and antitumor properties.

Conclusion: The obtained data suggest that the essential oil, methanol extract and methanol fractions of $C$. nudiflora possess remarkable antioxidant activities and vital phytochemicals. Thus the plant can be a utilized as a potential source of nutraceutical with antioxidant activity.

Keywords: Commelina nudiflora, Phytochemical compounds, Antioxidants, Methanol extract

(C) 2018 The Authors. Published by Innovare Academic Sciences Pvt Ltd. This is an open access article under the CC BY license (http://creativecommons.org/licenses/by/4.0/) DOI: http://dx.doi.org/10.22159/ijpps.2018v10i8.25922

\section{INTRODUCTION}

Synthetically prepared drugs are utilized worldwide for the treatment of various diseases. However, these drugs have several side effects such as gastric ulcer, kidney damage as well as cardiac abnormities [1]. Plants have been used as an important source of medicine for centuries. In recent years a large number of researchers have focused on medicinal plants due to fewer side effects and high efficacy. The natural product obtained from medicinal plants include flavonoids, polyphenols and alkaloids show immense pharmacological significance such as anti-inflammatory, antimicrobial, antioxidant and anticancer activities [2-4].

Commelina nudiflora, herbal plant and member of family Commelinaceae. The English name is "Day Flower" while the local Malay name is "Rumpur Aur". The glabrous and fleshy stem grows up to $15-30 \mathrm{~cm}$ in length with roots at the nodes. The plant is consists of simple green leaves and pink or purple color small flowers [5]. C. nudiflora is edible by humans. In India, the young stem of the plant is steamed and eaten as a vegetable in daily diet [6] while the young leaves and small flowers are consumed fresh in salads or boiled with butter $[7,8]$. The plant is also used for the treatment of the variety of diseases such as diarrhea, hemorrhoids, tuberculosis, eyes, ear, and throat diseases, mumps, boils, leprosy, antidote, gonorrhea and infertility treatments [9]. As the plant is used for the treatment of various diseases but no research has been done to explain the phytochemical compassion and free radical scavenging effects of the essential oil and solvent extract. Thus In the current study, the essential oil, methanol extract, and methanol fractions obtained from Commelina nudiflora were investigated for the free radical scavenging effects and phytochemical analysis.

\section{MATERIALS AND METHODS}

\section{Chemicals}

$\alpha, \alpha$-diphenyl-picrylhadrazyl (DPPH), and gallic acid were purchased from Sigma. Extraction solvents, methanol, n-hexane, butanol, chloroform and ethyl acetate (HPLC grade) were purchased from Merck (Darmstadt, Germany). Lead acetate, sodium carbonate, aluminum chloride, potassium acetate, potassium sulfate, sodium hydroxide, sodium nitroprusside, hydrogen peroxide, sulfanilic acid, glacial acetic acid were all obtained from Merck, USA.

\section{Sample collection}

The fresh leaves of $C$. nudiflora were collected from the lower land of Papar, Sabah, Malaysia. The plant was harvested and packed in polyethylene bags. The identification of plants was confirmed by Mr. Julius Kulip and Mr. Johnny Gisil from the Institute of Tropical Biology and Conservation, University Malaysia Sabah. A voucher specimen (MDS003) was deposited at the Tropical Biology and Conservation Herbarium, University Malaysia Sabah.

\section{Extraction and fractionation}

Sixty grams of powder plant was extracted with $300 \mathrm{ml}$ of methanol using soxhlet method $\left(50-60{ }^{\circ} \mathrm{C}\right.$ and $\left.72 \mathrm{~h}\right)$. The methanol residues were removed from the extract using a vacuum rotary evaporator. The extract was further suspended in distilled water and successfully extracted with $\mathrm{n}$-hexane, ethyl acetate, chloroform and butanol solvent in a separatory funnel. The solvents were removed from the extracts under vacuum. The samples were kept at at- $80^{\circ} \mathrm{C}$ for $24 \mathrm{~h}$ and then lyophilized using a freeze drier. The freeze-dried samples were then stored in the freezer for further analysis [10]. 


\section{Isolation of essential oil}

The $C$. nudiflora leaves $(100 \mathrm{~g})$ were subjected to hydrodistillation for $5 \mathrm{~h}$ using a distillation type apparatus. The essential oils from the leaves were dried over anhydrous sodium sulfate and further extracted with diethyl ether.

\section{Determination of total phenolic content}

The total phenolic content was determined by FolinCiocalteu method [11] with slight modification. A stock solution of 1 $\mathrm{mg} / \mathrm{ml}$ was prepared. Folin-Ciocalteu reagent was prepared by 10 fold dilution (ratio 1:9). Briefly, $1.5 \mathrm{ml}$ of Folin-Ciocalteu reagent was mixed with $0.2 \mathrm{ml}$ of assay samples and mixed vigorously. After $5 \mathrm{~min} 1.5 \mathrm{ml}$ sodium carbonate $(60 \mathrm{~g} / \mathrm{l})$ was added to the mixture. Finally, the mixture was allowed to stand for $90 \mathrm{~min}$ in the dark at room temperature. The absorbance was measured at $725 \mathrm{~nm}$ against a blank. Gallic acid was used as a standard for the quantification of the phenolic compound. Concentrations of 0.01 , $0.02,0.04,0.08$ and $0.1 \mathrm{mg} / \mathrm{g}$ of gallic acid were used to plot the slandered calibration curve. The concentration of the total phenolic content was estimated as mg of gallic acid equivalent by using an equation obtained from the gallic acid calibration curve. The determination of phenolic compounds in all the fractions was carried out in triplicate.

\section{Determination of total flavonoid content}

The total flavonoid content was determined by using the aluminum chloride colorimetric method [12] with some modi fications. $0.25 \mathrm{ml}$ of sample was mixed with $1.25 \mathrm{ml}$ of distilled water and $0.075 \mathrm{ml}$ of sodium nitrate $(5 \%)$ in a tube. The mixture was mixed vigorously and left in the dark for $6 \mathrm{~min}$. Further $0.15 \mathrm{ml}$ aluminum chloride (10\%) was added to the mixture, shaken vigorously and left for $5 \mathrm{~min}$ at room temperature. Finally, $0.5 \mathrm{ml}$ of sodium hydroxide (4\%) was added to the mixture, followed by the addition of distilled water to obtain a final volume of $2.5 \mathrm{ml}$. The mixture was thoroughly mixed by vortex. The absorbance was measured by spectrophotometer at $510 \mathrm{~nm}$ against the blank. Catechin was used as a standard with concentration at 0.02 , $0.04,0.06,0.08,0.1$ and $0.2 \mathrm{mg} / \mathrm{g}$. The calculation of total flavonoids in the extracts was done in triplicate and the results were averaged. The total flavonoid content was expressed in $\mathrm{mg}$ of catechin equivalents per gram of plant extract.

\section{Radical scavenging activity using the DPPH method}

The antioxidant activity of the essential oil, methanol extract and fractions was determined by DPPH assay [13]. A stock solution of 1 $\mathrm{mg} / \mathrm{ml}$ was prepared. Six concentrations $(0.012,0.025,0.050,0.1$ and $0.5 \mathrm{mg} / \mathrm{g}$ ) of essential oil, extract and fractions were used. During the process, $0.3 \mathrm{ml}$ of our diluted sample was mixed with 2.7 $\mathrm{ml}$ DPPH $(150 \mu \mathrm{M})$ in absolute methanol and left in the dark for 60 min. Absolute methanol was used as a blank. The absorbance was measured at 512 using spectrophotometer. Ascorbic acid was used as a standard. The radical-scavenging activity was calculated according to the formula summarized below.

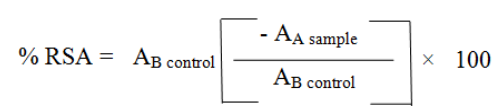

\% RSA: Percentage of radical scavenging activities.

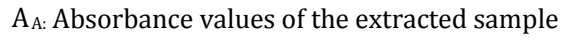

$A_{B}$ : Absorbance values of the control sample

\section{Determination of the effective concentration $\left(\mathrm{EC}_{50}\right)$}

The $\mathrm{EC}_{50}$ values express the amount of essential oil, methanol extract and methanol fractions required to reduce the absorbance of DPPH by $50 \%$ [14]. The values were determined by using the slope of the linear regression.

\section{Preliminary phytochemical screening}

The preliminary phytochemical screening of the methanol extract and methanol fractions $(\mathrm{Img} / \mathrm{ml})$ of $C$. nudiflora was carried out to determine the presence and absence of different phytochemical compounds. The plant extracts were screened for alkaloids, steroids, flavonoids, triterpenoids, saponins, tannins, anthraquinones and phytosterol $[15,16]$.

\section{Gas chromatography-mass spectrometry (GCMS) analysis}

Essential oil, methanol extract and methanol fractions of $C$. nudiflora were injected into a GCMS system consisting of an Agilent 7890A gas chromatograph system coupled with an Agilent 5975C mass spectrometry detector. A capillary column HP-5MS $(30 \mathrm{~m} \times 0.25 \mathrm{~mm})$ of $0.25 \mu \mathrm{m}$ film thickness of the coated material was used. The injector temperature was set at $250{ }^{\circ} \mathrm{C}$, the temperature arrangements were as follow: initiate at $40{ }^{\circ} \mathrm{C}$ and hold for $3 \mathrm{~min}$; from 40 to $200^{\circ} \mathrm{C}$ at $3{ }^{\circ} \mathrm{C} / \mathrm{min}$ and then hold for $3 \mathrm{~min}$. A post-run of $5 \mathrm{~min}$ at $200{ }^{\circ} \mathrm{C}$ was set for the next injection. Helium gas $(99.9 \%$ pure) was utilized as a carrier gas and maintained at $1.0 \mathrm{ml} / \mathrm{min}$ constant flow rate. Split-fewer modes were used. Identification of phytochemicals was done out by referring to National Institute of Standards and Technology (NIST) library and the compositions were computed with reference to the abundance of the compounds in the chromatogram. Each analysis was carried out in triplicate.

\section{Data analysis}

The experimental results were expressed as mean \pm SD. All the assays were performed in triplicate.

\section{RESULTS}

The percentage yield, total phenol and flavonoid contents of $C$. nudiflora methanol extract and methanol fractions

Table 1 shows the percentage of extraction yields, total phenolic and flavonoid contents of methanol extracts and methanol fractions (hexane, ethyl acetate, chloroform, and butanol) of $C$. nudiflora. There were significant differences among the methanol extract and methanol fractions.

Table 1: The percentage yield, total phenol and flavonoid contents of $C$. nudiflora methanol extract and methanol fractions

\begin{tabular}{llll}
\hline Extract/fractions & Percentage (\%) yield & Total phenolic content (mg/g) & Total flavonoid contents.(mg/g) \\
\hline Methanol extract & $11.22 \pm 0.58$ & $42.67 \pm 1.78$ & $31.54 \pm 2.23^{\mathrm{a}}$ \\
Hexane fraction & $1.33 \pm 0.08$ & $37.67 \pm 1.34$ & $24.32 \pm 2.06^{\mathrm{b}}$ \\
Ethyl acetate fraction & $0.64 \pm 0.10$ & $59.33 \pm 0.76$ & $52.78 \pm 2.20^{\mathrm{c}}$ \\
Chloroform fraction & $0.35 \pm 0.01$ & $43.50 \pm 2.42$ & $34.6 \pm 2.55$ \\
Butanol fraction & $0.43 \pm 0.06$ & $71.50 \pm 1.85^{\mathrm{e}}$ & $66.19 \pm 1.97 \mathrm{e}$ \\
\hline
\end{tabular}

Results are expressed as mean \pm SD $(n=3)$., Different letters with each mean a statistical difference.

DPPH scavenging activity of $C$. nudiflora essential oil, methanol extracts and methanol fractions

The DPPH free radical scavenging activity of the $C$. nudiflora essential oil, methanol extracts and methanol fractions was estimated at various concentrations ranging from $0.012-0.5 \mathrm{mg} / \mathrm{g}$. DPPH scavenging elevated with the concentration increase of essential oil, extract and fractions of our samples (fig. 1).
Data presented as mean \pm standard error of mean (SEM) value of three replicates

Calculated effective concentration (EC50) of $C$. nudiflora essential oil, methanol extract, and methanol fractions

Table 2 shows the $\mathrm{EC}_{50}$ values of the standard (ascorbic acid), $C$. nudiflora essential oil, methanol extracts and methanol fractions. 


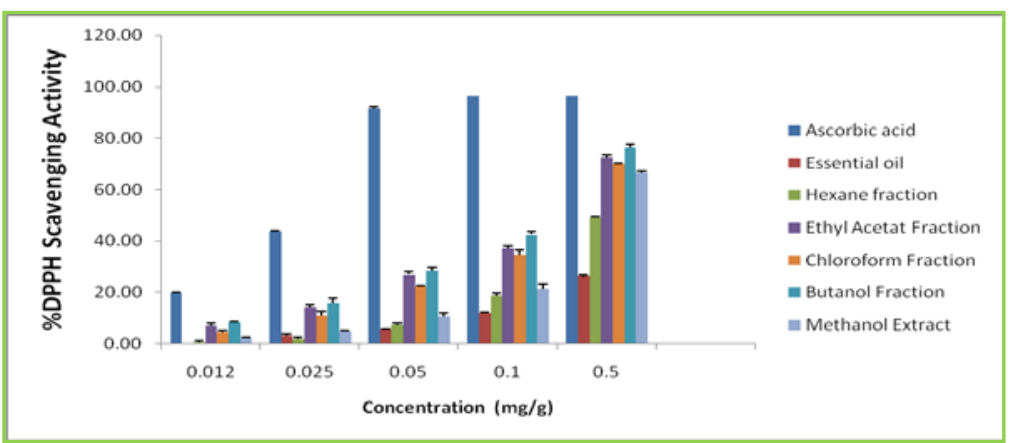

Fig. 1: Radical scavenging activity of $C$. nudiflora essential oil methanol extract and methanol fractions

Table 2: The EC50 values of ascorbic acid, essential oil, methanol extract and methanol fractions

\begin{tabular}{|c|c|}
\hline Extract/Fractions & $\mathrm{EC}_{50}(\mathrm{mg} / \mathrm{g})$ \\
\hline Ascorbic acid & $0.054 \pm 0.002$ \\
\hline Essential oil & $0.958 \pm 0.008$ \\
\hline Hexane friction & $0.496 \pm 0.004$ \\
\hline Ethyl acetate friction & $0.299 \pm 0.005$ \\
\hline Chloroform friction & $0.321 \pm 0.001$ \\
\hline Butanol friction & $0.277 \pm 0.005$ \\
\hline Methanol extract & $0.364 \pm 0.006$ \\
\hline
\end{tabular}

Results are expressed as mean \pm SD ( $n=3$ )., Different letters with each mean a statistical difference.

Phytochemical analysis of $C$. nudiflora methanol extracts and methanol fractions

The preliminary phytochemical screening of $C$. nudiflora methanol extracts and fractions indicated the presence of bioactive components such as alkaloids, flavonoids, phytosterols, saponins, tannins, triterpenoids, and steroids while anthraquinones were absent as shown in table 3.
Gas chromatography and mass spectrometry analysis of $C$. nudiflora essential oil, methanol extract, and methanol fractions

The phytochemical compounds exist in the essential oil, methanol extract and methanol fractions of $C$. nudiflora were identified by GCMS (fig. 2 to 7).

Table 3: The analysis of phytochemical in the methanol extract and methanol fractions of $C$. nudiflora

\begin{tabular}{|c|c|c|c|c|c|}
\hline \multirow[t]{2}{*}{ Biochemical } & \multicolumn{5}{|c|}{ Extract/Fractions } \\
\hline & Hexane & Ethyl acetate & Chloroform & Butanol & Methanol \\
\hline Alkaloids & ++ & + & + & + & ++ \\
\hline Anthraquinones & - & - & - & - & - \\
\hline Flavonoids & + & ++ & ++ & ++ & ++ \\
\hline Phytosterol & + & ++ & ++ & ++ & + \\
\hline Saponins & - & + & - & - & + \\
\hline Tannins & - & + & + & + & + \\
\hline Triterpenoids & + & + & + & + & ++ \\
\hline Steroids & + & + & + & + & + \\
\hline
\end{tabular}

+= present; ++= Strong presence; -= absent.

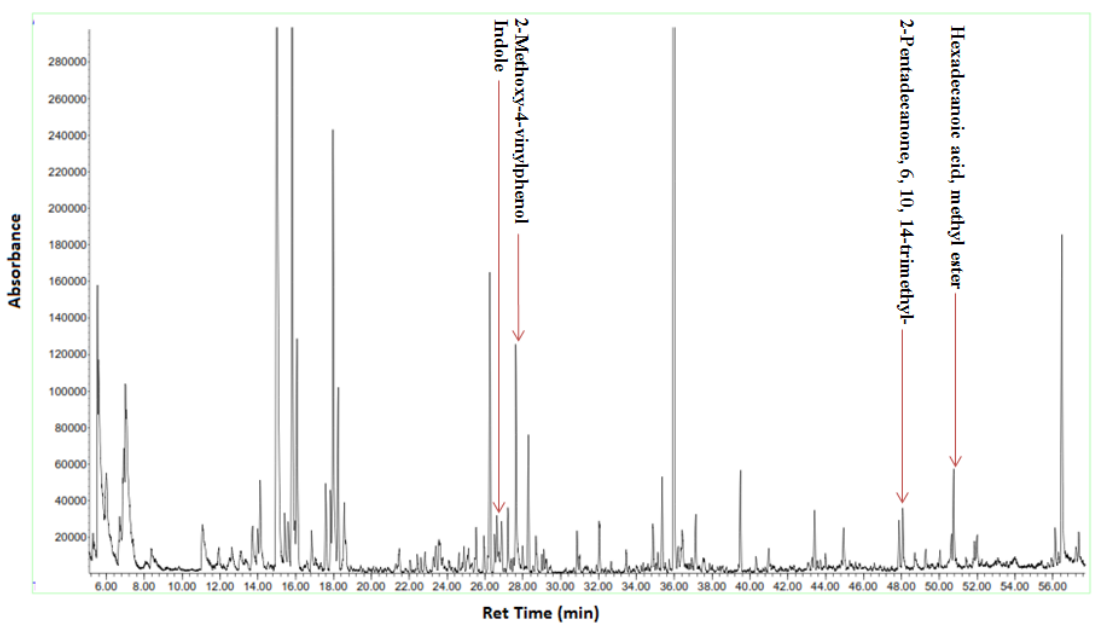

Fig. 2: A typical gas chromatogram of the chemical constituents of essential oil of C. nudiflora 


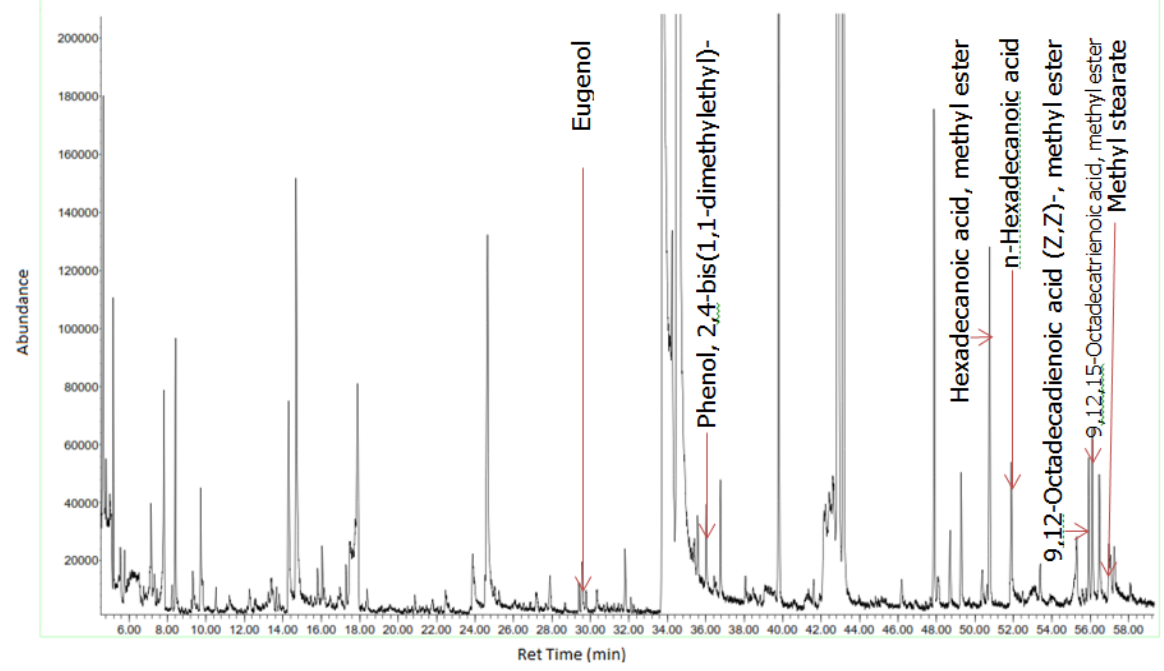

Fig. 3: GC-MS chromatogram of the hexane fraction of methanol extract of $C$. nudiflora plant

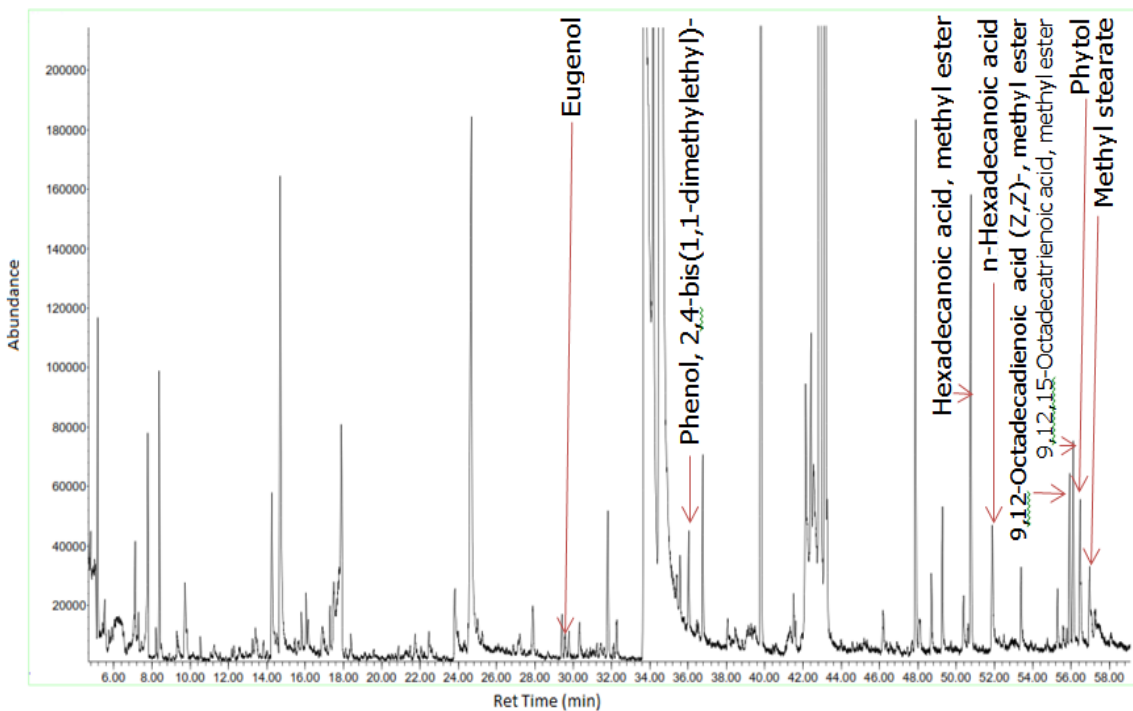

Fig. 4: GC-MS chromatogram of the ethyl acetate fraction of methanol extract of $C$. nudiflora plant

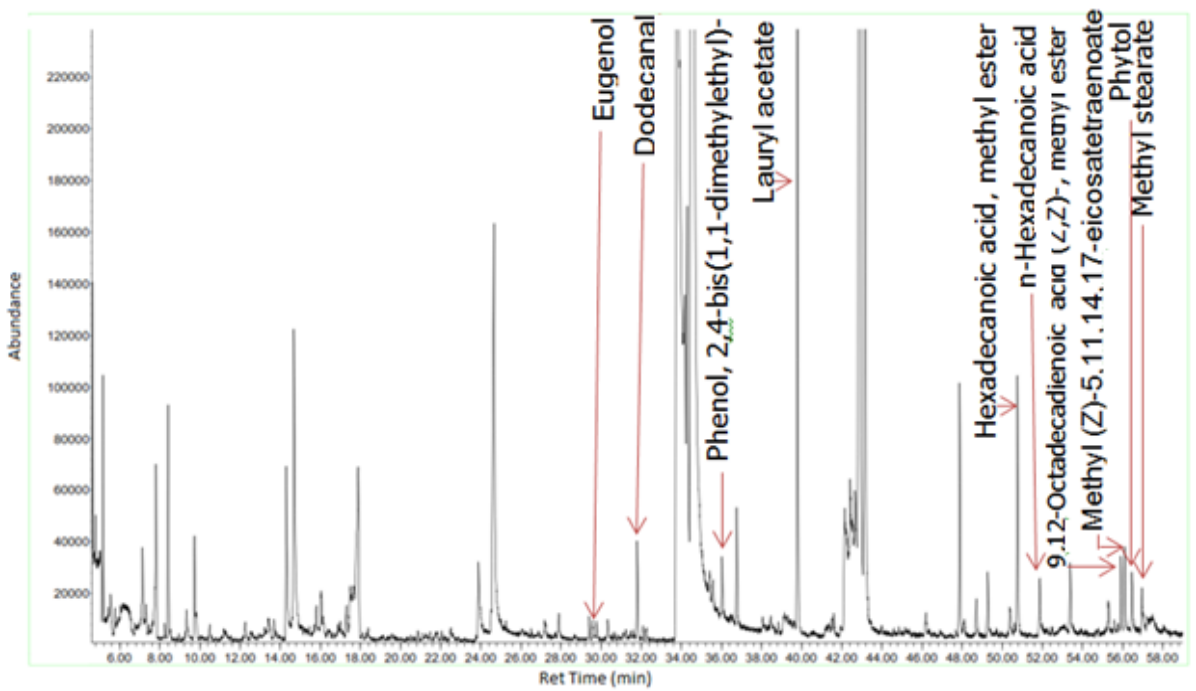

Fig. 5: GC-MS chromatogram of the chloroform fraction of methanol extract of $C$. nudiflora plant 
Table 4: The phytochemical compounds detected in the essential oil, methanol extract and methanol fractions of $C$. nudiflora

\begin{tabular}{|c|c|c|c|c|}
\hline E. oil/extract/fractions & No & Compound name & RT & Area (\%) \\
\hline & 1. & Indole & 26.72 & 4.30 \\
\hline \multirow[t]{6}{*}{ E. oil } & 2. & 2-Methoxy-4-vinylphenol & 27.63 & 48.30 \\
\hline & 3. & 3-Buten-2-one, 4-(2,6,6-trimethyl-1-cyclohexen-1-yl)- & 34.87 & 10.55 \\
\hline & 4 & $\begin{array}{l}\text { 1-Naphthalenol, 1,2,3,4,4a,7,8,8a-octahydro-1,6-dimethyl-4-(1-methylethyl)-, } \\
\text { [1R-(1. alpha.,4. beta.,4a. beta.,8a. beta.)]- }\end{array}$ & 40.98 & 5.34 \\
\hline & 5. & 2-Pentadecanone, 6,10,14-trimethyl- & 48.06 & 13.55 \\
\hline & 6. & Hexadecanoic acid, methyl ester & 50.75 & 17.95 \\
\hline & 1. & Undecane & 17.29 & 2.12 \\
\hline \multirow[t]{11}{*}{ n-Hexane } & 2. & 2H-Pyran-2-one, 4,6-dimethyl- & 22.47 & 0.99 \\
\hline & 3. & Eugenol & 29.57 & 2.68 \\
\hline & 4. & 2-Fluorobenzoic acid. heptadecyl ester & 35.58 & 7.47 \\
\hline & 5. & Phenol, 2,4-bis(1,1-dimethylethyl)- & 36.03 & 7.50 \\
\hline & 6. & Cyclododecane & 39.79 & 35.33 \\
\hline & 7. & Hexadecanoic acid, methyl ester & 50.76 & 16.27 \\
\hline & 8. & n-Hexadecanoic acid & 51.90 & 8.61 \\
\hline & 9. & 9,12-Octadecadienoic acid (Z,Z)-, methyl ester & 55.92 & 6.12 \\
\hline & 10. & $9,12,15$-Octadecatrienoic acid, methyl ester, $(\mathrm{Z}, \mathrm{Z}, \mathrm{Z})$ - & 56.11 & 7.85 \\
\hline & 11. & Methyl stearate & 56.97 & 2.78 \\
\hline & 12. & (R)-(-)-14-Methyl-8-hexadecyn-1-ol & 57.05 & 2.28 \\
\hline \multirow[t]{11}{*}{ Ethyl acetate } & 1. & $\mathrm{~N}$-. alpha.,N-. omega.-Di-cbz-L-arginine & 14.52 & 1.65 \\
\hline & 2. & 2H-Pyran-2-one, 4,6-dimethyl- & 22.46 & 1.08 \\
\hline & 3. & Eugenol & 29.57 & 1.34 \\
\hline & 4. & Phenol, 2,4-bis(1,1-dimethylethyl)- & 36.03 & 9.69 \\
\hline & 5. & 1,1'-Biphenyl, 2,2',5,5'-tetramethyl- & 42.14 & 23.73 \\
\hline & 6. & Hexadecanoic acid, methyl ester & 50.76 & 21.27 \\
\hline & 7. & n-Hexadecanoic acid & 51.89 & 7.92 \\
\hline & 8. & 9,12-Octadecadienoic acid (Z,Z)-, methyl ester & 55.92 & 7.83 \\
\hline & 9. & $9,12,15$-Octadecatrienoic acid, methyl ester, $(\mathrm{Z}, \mathrm{Z}, \mathrm{Z})$ - & 56.10 & 10.79 \\
\hline & 10. & Phytol & 56.46 & 8.48 \\
\hline & 11. & Methyl stearate & 56.96 & 6.20 \\
\hline \multirow[t]{11}{*}{ Chloroform } & 1. & Eugenol & 29.56 & 1.45 \\
\hline & 2. & Dodecanal & 31.8 & 6.14 \\
\hline & 3. & Phenol, 2,4-bis(1,1-dimethylethyl)- & 36.03 & 8.73 \\
\hline & 4. & Lauryl acetate & 39.79 & 42.19 \\
\hline & 5. & Hexadecanoic acid, methyl ester & 50.75 & 15.86 \\
\hline & 6. & n-Hexadecanoic acid & 51.86 & 4.49 \\
\hline & 7. & 9,12-Octadecadienoic acid (Z,Z)-, methyl ester & 55.92 & 4.85 \\
\hline & 8. & Methyl (Z)-5,11,14,17-eicosatetraenoate & 56.11 & 6.70 \\
\hline & 9. & Phytol & 56.46 & 5.33 \\
\hline & 10. & Heptadecanoic acid, 16-methyl-, methyl ester & 56.96 & 4.20 \\
\hline & 1. & Phenol, 2,4-bis(1,1-dimethylethyl)- & 36.02 & 4.01 \\
\hline \multirow[t]{8}{*}{ Butanol } & 2. & Fluoroacetic acid, dodecyl ester & 39.79 & 37.80 \\
\hline & 3. & Hexadecanoic acid, methyl ester & 50.75 & 27.06 \\
\hline & 4. & n-Hexadecanoic acid & 51.86 & 3.80 \\
\hline & 5. & 9,12-Octadecadienoic acid (Z,Z)-, methyl ester & 55.91 & 7.15 \\
\hline & 6. & 9,12,15-Octadecatrien-1-ol, $(\mathrm{Z}, \mathrm{Z}, \mathrm{Z})$ - & 56.10 & 10.88 \\
\hline & 7. & Phytol & 56.46 & 4.96 \\
\hline & 8. & Methyl Stearate & 56.96 & 4.26 \\
\hline & 1. & Acetic acid & 3.39 & 1.60 \\
\hline \multirow[t]{19}{*}{ Methanol } & 2. & Phenol & 12.54 & 0.71 \\
\hline & 3. & Benzyl alcohol & 14.35 & 1.62 \\
\hline & 4. & Undecane & 17.29 & 2.00 \\
\hline & 5. & Caprolactam & 24.77 & 6.83 \\
\hline & 6. & Eugenol & 29.06 & 0.64 \\
\hline & 7. & Cyclododecane & 33.83 & 36.17 \\
\hline & 8. & 1-Decene & 34.2 & 9.30 \\
\hline & 9. & Phenol, 2,4-bis(1,1-dimethylethyl) & 36.06 & 0.77 \\
\hline & 10. & $2(4 \mathrm{H})$-Benzofuranone, 5,6,7,7a-tetr ahydro-4,4,7a-trimethyl-, (R) & 36.48 & 0.52 \\
\hline & 11. & Dodecanoic acid & 38.1 & 0.70 \\
\hline & 12. & Lauryl acetate & 39.83 & 5.64 \\
\hline & 13. & Pentafluoropropionic acid, undecyl ester & 42.66 & 3.32 \\
\hline & 14. & Hexadecanoic acid ethyl ester & 50.79 & 2.27 \\
\hline & 15. & n-Hexadecanoic acid & 51.95 & 3.15 \\
\hline & 16. & $9,12-$-Octadecadienoic acid, methyl ester & 55.95 & 1.14 \\
\hline & 17. & Cyclooctene, 3 ethenyl & 56.15 & 1.25 \\
\hline & 18. & Phytol & 56.71 & 2.61 \\
\hline & 19. & Methyl stearate & 57.01 & 0.48 \\
\hline & 20. & 9,12 -Octadecadienoic acid (Z,Z)- & 57.10 & 0.66 \\
\hline
\end{tabular}




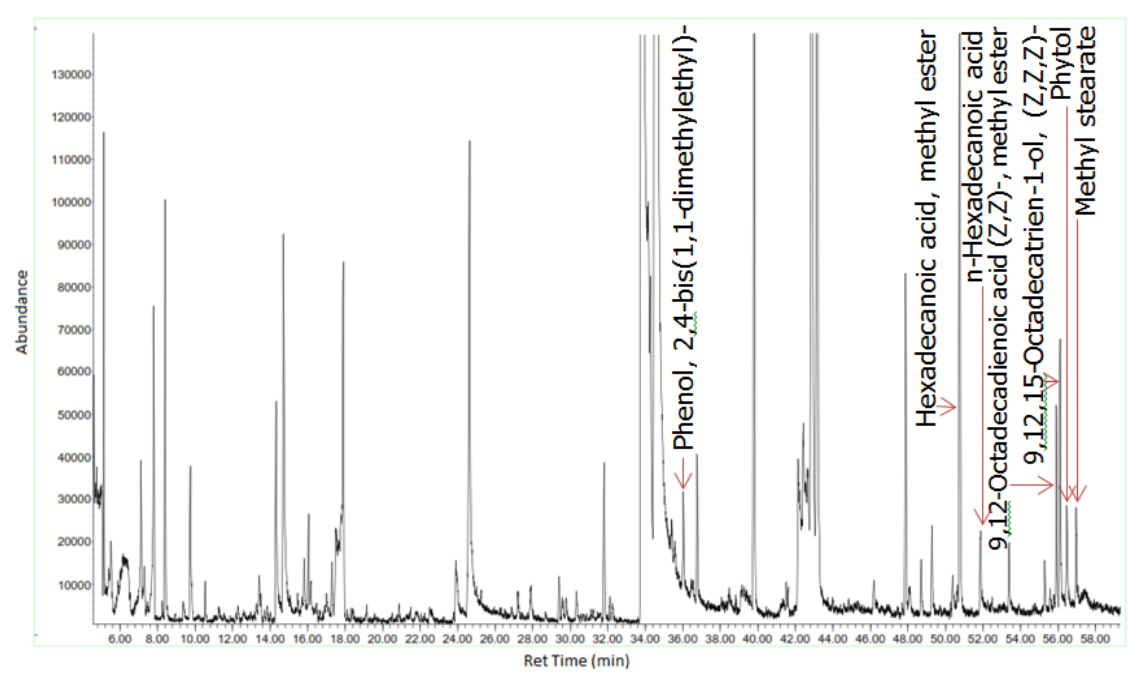

Fig. 6: GC-MS chromatogram of the butanol fraction of methanol extract of $C$. nudiflora plant

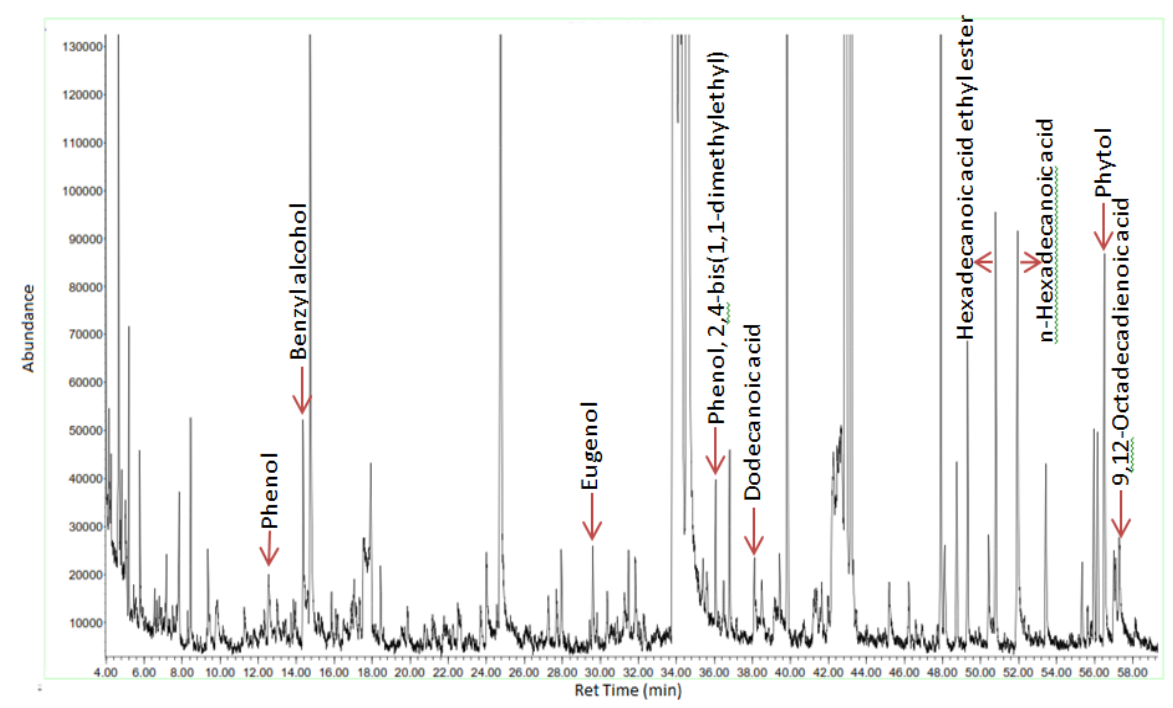

Fig. 7: GC-MS chromatogram of the methanol extract of $C$. nudiflora plant

The phytochemical compounds detected in the essential oil, methanol extract and methanol fractions of $C$. nudiflora

The list of the compound detected in the essential oil, methanol extract and methanol fraction of C. nudiflora is shown in the table along with retention time and area percentage as shown in table 4 .

\section{DISCUSSION}

C. nudiflora is consumed as a traditional remedy for the treatment of various types of disease. Previously, there has been no study of $C$. nudiflora relevant to its antioxidant activity and phytochemical analysis.

Phenolics are important metabolites of plants with antioxidant potential due to their redox properties. The compounds are essential for decomposition and neutralization of free radicals [17]. The data recorded in the current study showed that the phenolic compound level in butanol, ethyl acetate, chloroform fractions and methanol extract of $C$. nudiflora is very high. Flavonoids are important and diverse phenolic substances, isolated from a large number of plants. These compounds possess antioxidant, antiviral, anti-inflammatory and anti-allergenic activities [18]. Thus it was important to evaluate the amounts of flavonoids in methanol extract and methanol fractions. The hexane fractions of methanol extract showed lower flavonoid values $(4.61 \pm 0.16$ and $24.32 \pm 2.06)$ as compared to Butanol, (66.19 \pm 1.97$)$, ethyl acetate $(52.78 \pm 2.20)$ and chloroform fractions $(34.65 \pm 2.55 \mathrm{mg} / \mathrm{g}$ ) (table 1$)$.
The antioxidantive effect on DPPH is believed to be due to hydrogen donation ability [19]. The essential oil, methanol extract, and fractions of $C$. nudiflora indicated less DPPH radical scavenging activities in comparison to ascorbic acid as shown in fig. 1. Our results showed that the essential oil, methanol extract and methanol fractions of $C$. nudiflora possess proton donating potential and could play a crucial role in free radical scavenging and inhibition. The phytochemical analysis of methanol extract and methanol fractions of $C$. nudiflora is shown in table 3 indicates the presence of medicinally active compounds such as alkaloids, tannins, steroids, phytosterol, saponin, triterpenoids, and flavonoids. Studies have shown that these compounds exhibit several pharmacological properties such as anticholinergic, vasodilating, anti-hypertensive, anti-bacterial, antiviral and anti-tumour [19, 20].

In the essential oil, methanol extract and methanol fractions of $C$. nudiflora several bioactive compounds have been noticed. The identified bioactive compounds include indole, an aromatic heterocyclic organic compound. The derivatives of the compound have been reported with antimicrobial and anti-inflammatory properties [21]. 2-Methoxy-4-vinyl phenol has been also reported in the extract of Pergularia daemia with anti-microbial, analgesic, anti-oxidant and anti-inflammatory by Sridevi et al. [22]. 2-Pentadecanone, 6,10,14trimethyl-has been reported with antimicrobial properties by Govindappa et al. [23], phenol, which is a sample phenolic compound with one hydroxyl group. This compound has been reported in 
the Ficus religiosa linn ethanol bark extract with antioxidant, antiseptic and anti-bacterial properties [24]. Benzyl alcohol, an aromatic alcohol compound with a benzene ring, has also been reported in basil leaves (Ocimum basilicum $L$ ) with antioxidant and anti-microbial properties [25-27]. Eugenol is a phenolic compound and has been found in the extract of basil leaves (Ocimum basilicum L) and Eugenia caryophyllata with antioxidant and anti-inflammatory properties [25, 28, 29]. Phenol, 2,4-bis (1,1-dimethylethyl) is an alkylated phenolic compound and has also been reported in the extracts of Plumbago zeylanica and Tephrosia tinctoria with antioxidant, anti-cancer and anti-microbial properties [30, 31]. Dodecanoic acid is also known as lauric acid. It is a saturated fatty acid and has been found in the extract of Vitex altissima $L$ with antimicrobial, antioxidant, anti-viral and hypocholesterolemic properties [32-34]. Hexadecanoic acid and nHexadecanoic acid have been found in the extract of Vitex negundo and Centaurea aladagensis and have been reported with antioxidant and hypocholesterolemic properties [35, 36]. Phytol, a diterpene alcohol, has also been noticed in the Hybanthus enneaspermus and reported with anti-microbial, anti-cancer, antiinflammatory, hepatoprotective and diuretic activities [35, 37]. 9,12Octadecadienoic acid is commonly known as linoleic acid. It is an unsaturated fatty acid. The compound has also been reported in Scotia brachypetala with anti-inflammatory, anti-cancer and hepatoprotective properties $[35,38,39]$.

\section{CONCLUSION}

Our current data suggest that the essential oil, methanol extract and methanol fractions of $C$. nudiflora possess remarkable antioxidant activities and vital phytochemicals with antioxidant, antiinflammatory, antimicrobial and antitumor activities. Thus the plant can be a used as a potential source of nutraceutical with antioxidant activity. This study was the first report about the antioxidant activities and phytochemical analysis of $C$. nudiflora essential oil, methanol extract and methanol fractions. Further investigation to determine antioxidant activity by the in vivo method is in progress in our laboratory.

\section{ACKNOWLEDGEMENT}

This research work is financially supported by Ministry of Higher Education, Malaysia grant-in-aid No.: FRG0411-SG-1/2015. The authors are grateful to Dr. Zarina Amin, Director of Biotechnology Research Institute for her support and encouragement. MDS is also thankful to the Ministry of Education (MOE), Malaysia for providing research fellowship (Ref No: KPT. B.600-18/3/-0R212688).

\section{AUTHORS CONTRIBUTIONS}

Muhammad Dawood Shah-Conducted the experiment and prepared the manuscript. Dr. Mohammad Iqbal-Helped in designing and conducting the experiment.

\section{CONFLICT OF INTERESTS}

The authors declare that there are no conflicts of interest.

\section{REFERENCES}

1. Burke A, Smyth E, Fitzgerald GA. Analgesic-antipyretic agents: pharmacotherapy of gout. Brunton LL, Lazo JS, Parker KL. Eds. Goodman and Gilmans the Pharmacological Basis of Therapeutics, New York: McGraw Hill; 2006.

2. Shukla S, Mehta A, Mehta P, Vyas SP, Shukla S, Bajpai VK. Studies on anti-inflammatory, antipyretic and analgesic properties of Caesalpinia bonducella $F$. seed oil in experimental animal models. Food Chem Toxicol 2010;48:61-4.

3. Konate K, Hilou A, Mavoungou JF, Lepengue AN, Souza A, Barro $\mathrm{N}$, et al. Antimicrobial activity of polyphenol-rich fractions from Sidaalba L. (Malvaceae) against co-trimoxazol-resistant bacteria strains. Ann Clin Microbiol Antimicrob 2012;11:5.

4. Cai Y, Luo Q, Sun M, Corke H. Antioxidant activity and phenolic compounds of 112 traditional Chinese medicinal plants associated with anticancer. Life Sci 2005;74:2157-84.
5. Gallinato MI, Moody K, Piggin CM. Uplamd rice weeds of south and southeast Asia International Rice Research Institute Los Banos; 1999. p. 33.

6. Hedrick UP. Sturtevant's edible plants of the world. Dover publications, ISBN 0-486-20459-6; 1972.

7. Duke JA, Ayensu ES. Medicinal plants of China. Reference Publications, Inc; 1985.

8. Leonard DB. Medicine at your feet: Healing plants of the Hawaiian Kingdom. Vol. I; 2006.

9. Alikbangon Philippines medicinal plants. Available from; http://www.stuartxchange.org/Alikbangon.html. [Last accessed on 30 Apr 2017]

10. Khan RA, Khan MR, Sahreen S, Shah NA, Bokhari J, Rashid U, et al. Phytotoxic characterization of various fractions of Launaea nudicaulis. J Med Plants Res 2012;6:1403-6.

11. Velioglu YS, Mazza G, Gao L, Oomah BD. Antioxidant activity and total phenolics in selected fruits, vegetables, and grain products. J Agric Food Chem 1998;46:4113-7.

12. Zou YP, Lu YH, Wei DZ. Antioxidant activity of a flavonoid-rich extract of Hypericum perforatum L. in vitro. J Agric Food Chem 2004;52:5032-9.

13. Hatano T, Kagawa H, Yasuhara T, Okuda T. Two new flavonoids and other constituents in liquorice root: their relative astringency and radical scavenging effects. Chem Pharm Bull 1988;36:1090-7.

14. Antolovic M, Prenzler PD, Patsalides E, McDonald S, Robards K Methods for testing antioxidant activity. Analyst 2002;127:183-98.

15. Harborne JB. Phytochemical methods. A guide to modern techniques of plant analysis. $3^{\text {rd }}$ ed. New York: Chapman and Hall Int; 1998.

16. Trease GE, Evans WC. Textbook of Pharmacognosy. 12 $12^{\text {th }}$ ed. Londen: Balliere Tindall; 1989.

17. Zheng W, Wang SY. Antioxidant activity and phenolic compounds in selected herbs. J Agric Food Chem 2001;49:5165-70.

18. Pietta PG. Flavonoids as antioxidants. J Nat Prod 2000;63:103542.

19. Cordell GA. Introduction to alkaloids. Abiogenic approach. New York: Wiley; 1983.

20. Heslem E. Plant polyphenol: vegetal tannin relisted-chemistry and pharmacology of natural products. United Kingdem: Cambridge University Press; 1989. p. 169.

21. Gopinath S, Sakthidevi G, Muthukumara Swamy S, Mohan VR. GC-MS analysis of bioactive constituents of Hypericum mysorense (Hypericaceae). J Curr Chem Pharm Sci 2013;3:6-15.

22. Sridevi G, Sembulingam $P$, Suresh S, Sembulingam K. Phytochemical analysis of Pergularia daemia for Its bioactive components through gas chromatographic mass spectrometry (GCMS). IOSRPHR 2014;4:41-6.

23. Govindappa M, Prathap S, Vinay V, Channabasava R. Chemical composition of methanol extract of endophytic fungi, Alternaria sp. of Tebebuia argentea and their antimicrobial and antioxidant activity. Int J BioPharma Res 2014;5:861-9.

24. Saravanan P, Chandramohan G, Mariajancyrani J, Shanmugasundaram P. GC-MS analysis of phytochemical constituents in ethanolic bark extract of Ficusreligiosa Linn. Int J Pharm Pharm Sci 2014;6:457-60.

25. Lee KG, Shibamoto T. Determination of antioxidant potential of volatile extracts isolated from various herbs and spices. J Agric Food Chem 2002;50:4947-52.

26. Lee SJ, Umano K, Shibamoto T, Lee KG. Identification of volatile components in basil (Ocimum basilicum L.) and thyme leaves (Thymus vulgaris L.) and their antioxidant properties. Food Chem 2005;91:131-7.

27. Dasgupta A, Humphrey PE. Gas chromatographic-mass spectrometric identification and quantitation of benzyl alcohol in serum after derivatization with perfluorooctanoyl chloride: a new derivative. J Chromatogr B Biomed Sci Appl 1998; 708:299-303.

28. Politeo O, Jukic M, Milos M. Chemical composition and antioxidant capacity of free volatile aglycones from basil (Ocimum basilicum L.) compared with its essential oil. Food Chem 2006;101:379-85. 
29. Apparecido N, Daniel SM, Sartoretto GSSM, Schimidt G, Caparroz Assef SM, Bersani-Amado CA, Cuman RK. Antiinflammatory and antinociceptive activities of eugenol essential oil in experimental animal models. Braz J Otorhinolaryngol 2009;19:212-7.

30. Ajayi GO, Olagunju JA, Ademuyiwa O, Martins OC. Gas chromatography-mass spectrometry analysis and phytochemical screening of ethanolic root extract of Plumbago zeylanica, Linn. J Med Plants Res 2011;5:1756-61.

31. Rajaram K, Moushmi M, Velayutham Dass Prakash M, Kumpati $P$, Ganasaraswathi M, Suresh Kumar P. Bioactive studies between wild plant and callus culture of Tephrosia tinctoria Pers. Appl Biochem Biotech 2013;17:1-16.

32. Bativska D, Todorova IVAT, Tsvetkove IVAV, Najdenski HM. Antibacterial study of the medium chain fatty acids and their 1monglycerides: Individual effects and synergistic relationships. Pol J Microbiol 2009;58:43-7.

33. Ouattara B, Simard RE, Holley RA, Piette GJP, Begin A. Antibacterial activity of selected fatty acids and essential oils against six meat spoilage organisms. Int J Food Microb 1997;37:155-62.

34. Sathish SS, Janakiraman N, Johnson M. Phytochemical analysis of Vitex altissima L. using UV-VIS, FTIR and GC-MS. Int J Sci Res 2012;4:56-62.

35. Kumar PP, Kumaravel S, Lalitha C. Screening of antioxidant activity, total phenolics and GC-MS study of Vitex negundo. Afr J Biochem Res 2010;4:191-5.

36. Bulent Kose Y, Iscan G, Demirci B, Başer KH, Celik S. Antimicrobial activity of the essential oil of Centaured aladagensis. Fitoterapia 2007;78:253-4.

37. Anand T, Gokulakrishnan K. Phytochemical analysis of Hybanthusenneaspermus using UV, FTIR and GC-MS. IOSRPHR 2012;2:520-4.

38. McGaw LJ, Jager AK, Van Staden J. Isolation of antibacterial fatty acids from Schotia brachypetala. Fitoterapia 2002;73:431-3.

39. Zheng CJ, Yoo JS, Lee TY, Cho HY, Kim YH, Kim WG. Fatty acid synthesis is a target for antibacterial activity of unsaturated fatty acids. FEBS Lett 2005;579:5157-62. 